\title{
Smart System to Prevent Axle Seizure in Rolling Stocks (Trains)
}

\author{
Kartik Khandelwal \\ Veermata Jijabai Technological Institute, Matunga, Mumbai-400019
}

\begin{abstract}
Axle seizure is one of the major problems faced by the railways. The two main factors leading to axle seizure are bearing overheating and brake binding. This study, mainly concentrates on determining the exact location of the fault (i.e. bearing overheating or brake binding (Air brakes). A system is devised to detect and rectify the above mentioned faults. It consists of temperature sensors, pressure switches, GPS unit and solenoid valve to overcome the problem of detention of trains which results in loss of punctuality and to prevent damage to the profile and the wheels.
\end{abstract}

Keywords: Axle seizure, bearing overheating, brake binding, smart system

\section{Introduction}

Railways is facing the major problem of Axle seizure primarily due to bearing overheating and brake binding.

\subsection{Bearing Overheating}

Bearing overheating is caused due to lubrication failure, misalignment, electrical damage, fatigue(Spalling) and corrosion etc.

\subsection{Brake Binding}

Brake binding leading to generation of heat and smoke. Whenever brake block grips the wheel with excessive braking force, it is termed as brake binding. It is burning problem of the day in all types of rolling stock.

1.2.1 Repercussions of Bearing heating \& brake binding in operation are as under:

a) Detention of trains causing loss of punctuality.

b) Flat places on thetyre of wheel leading to bearing failure, rail fracture etc.

c) Ineffective percentage of coaching stock increases and thus, maintenance cost is also increasing.

d) More tractive force needed by locomotive to haul even light load train.

1.2.2 To overcome this problem a system called Smart Box is devised. Smart Box performs various functions: It determines the location and type of fault and passes on information to control room. Further, it also provides temporary rectification if the fault is caused due to brake binding.

\section{Smart System}

It consists of power generator, sensor control unit and master controller.

\subsection{Power Generator}

Power Generator for Goods Train (Power for passenger trains is available in coach itself).
The power is generated by using a small Air Circulating unit provided strategically for ease of maintenance and operation. The power so generated is stored and used through rechargeable batteries for continuous operation of the system.

\subsection{Sensor Control Unit}

It consists of the following components

1) Temperature sensor

2) GPS unit

3) Pressure switch

4) Solenoid valve

2.2.1Temperature sensor for detecting temperature of bearing on the under frame of the train coach. It can operate under extreme climatic conditions and it is vibration free.

2.2.2GPS unit enables real time analysis of the position and speed of the train. It calculates the coordinates of the train at all times.

2.2.3Pressure switch - Pressure switches are placed in the air brake pipe line to obtain information regarding the application of the brake.

Pressure switches have the following specifications:

a) They are suitable for gaseous media and air.

b) They are fitted with a single-pole switch changeover (SPDT)

c) Pressure ranges: -0.2 to 21 bar

d) High contact load - Ultra short bounce-time

e) Available with gold plated contact systems

f) (d) Media-Gaseous media and air

g) Small dimensions - space saving - easy to install

h) Shock and impact resistant.

i) Ambient temperature is -40 to 65 degree Celsius.

2.2.4Solenoid valve - It is placed in the air pipe line to obtain the information regarding the supply of air for the application of brake. Initially the solenoid valve is in the normally open state, once it receives the signal from the master controller it changes its state to normally closed. 


\section{International Journal of Science and Research (IJSR) \\ ISSN (Online): 2319-7064 \\ Index Copernicus Value (2015): 78.96 | Impact Factor (2015): 6.391}

Solenoid valve specifications are as follows:

a) Pressure range: up to 400 bar.

b) Operating temperature between $0{ }^{\circ} \mathrm{C}$ to $80^{\circ} \mathrm{C}$.

c) Orifice $-0.5 \mathrm{~mm}$ to $80 \mathrm{~mm}$ thus offering a wide range of flow rates.

d) Mounting - Any position.

e) Life: above 10 million cycles

\subsection{Master Controller Unit}

The master controller unit forms the heart of the system. It receives the command from the sensor control unit in case of a fault and after analysis of the signal it transmits the data to the control room and to the driver with location and type of fault.

Each master controller unit has a unique identity number, selectable using the DIP switches on the unit along with its position from driver which helps master controller unit to identity the coach position and coach number.

\subsubsection{Technical Specifications}

The master controller unit has the following features

(a) Input Supply: 12 volts from the rechargeable battery.

(b) Fault Scanning: Suitable through software switching

(c) Thumbwheel switch: 6 to 8 thumbwheel switch for setting the coach.

(d) Coach number selectable through thumbwheel switch.

(e) Coach position selectable through thumbwheel switch.

Table 1: Per Coach Specifications

\begin{tabular}{|c|c|}
\hline Components & Quantity \\
\hline Master Controller & 1 \\
\hline Temperature Sensor & 8 \\
\hline Pressure Switch & 2 \\
\hline Solenoid Valve & 2 \\
\hline GPS unit & 1 \\
\hline
\end{tabular}

In the figure 1 we have,

1-Solenoid Valve

2-Temperature Sensor

3-GPS unit

4-Wheels

5-Master Controller

6-Brake Air Pipe

The connections between the various components of a Smart System in a coach are also shown in figure 1 .

Coach

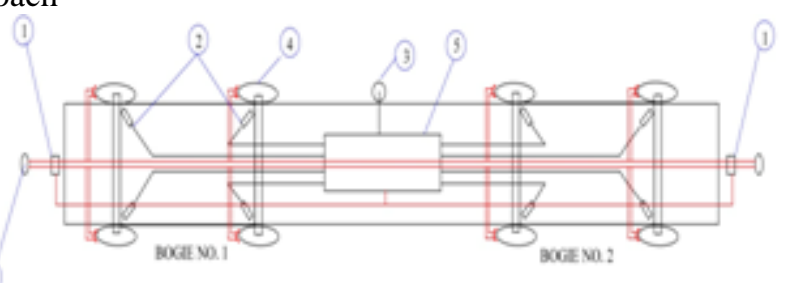

Figure 1: Layout of Smart System in the coach

\section{Logic to Analyze Faults}

Temperature data is taken from all four wheels of the bogie ( 2 Bogies are provided for each coach) and it is then sent to the master controller through a wired channel as shown in figure 1 . This signal is continuously analyzed by the master controller and once the abnormality is detected the master controller sends the signal to the control room through a wireless channel i.e GSM 900 channel indicating excessive heating.

Simultaneously, the master controller keeps a check on the fault caused due to brake binding.

A pressure switch is connected to the brake pipe line such that it operates when the brake is applied. This pressure switch is continuously monitored by the master controller.

The master controller also determines the time taken by the train to reduce to a certain desired speed from the initial speed, on the application of the brake. Then it compares this calculated (practical) time with the theoretical time. This process is repeated thrice in order to obtain highly accurate results. If the two practical and theoretical times do not match then the master controller sends the fault type and location to the main controller in the control room and to the driver of the train through a GSM 900 channel.

The main controller then checks the data from other master controllers and determines whether the brake are applied or not. If the brakes are not applied then it sends the signal to the master controller to operate the solenoid valve placed in the air pipe to isolate the coach.

\section{Conclusion}

Smart system is devised to prevent axle seizure due to excessive heating. It not only determines whether the fault (i.e. excessive heating) is due to bearing overheating or brake binding but also locates the fault and sends the alert signal to the driver and control room for necessary actions. Further, the system provides temporary rectification if the fault is caused due to brake binding. Temporary rectification ensures that emergency brake is not applied by the driver, thus maintaining the punctuality by avoiding detention of the train, preventing damage to the profile and the wheels, which otherwise would have become flat and most importantly avoiding axle seizure.

\section{Future Scope}

Further research can be done to upgrade this system by having a rectification method to avoid bearing overheating.

\section{References}

[1] Chris Wilson, corporate operations manager at Ritbearings Corporation. [Online]. Available.http://reliableplant.com/Read/30255/reasonsbearings-fail

[2] Brake Binding in coaching stocks [Online]. Available.http://trainguard.in/?page_id=1235

[3] Railway safety systems workshop at Kamal Automations Private Limited, Mumbai. 


\section{Author Profile}

Kartik Khandelwal is pursuing B.Tech in Electrical Engineering from VeermataJijabai Technological Institute, Mumbai. He is currently in the final year. 